\title{
Prioritization of indigenous fruit tree species with domestication and commercialization potential in KwaZulu-Natal, South Africa
}

\author{
Noluthando Nonjabulo Nkosi - Theodorus Hendrik Cornelis Mostert • \\ Sebinasi Dzikiti · Nontuthuko Rosemary Ntuli
}

Received: 5 September 2019/Accepted: 1 April 2020/Published online: 16 April 2020

(C) The Author(s) 2020

\begin{abstract}
Indigenous fruit tree species (IFTs) can play a crucial role in poverty alleviation and as a source of food in South Africa. Although these species contain nutrient-rich edible fruits that are also locally processed to food products such as jams and jellies, they are still underutilized and also harvested from the wild. This study aimed to prioritize in northern KwaZulu-Natal, IFTs with domestication and commercialization potential. A literature survey and focus groups were used to list tree species that produce edible fruits with this potential. Plant experts, through focus groups and reference group meetings, further ranked fruit trees using a scorecard method based on various attributes. A total of 29 prioritized IFTs was obtained, of which the Sapotaceae was the most represented family with a maximum of four species. Based on scorecard assessment, the most preferred species in descending order were Strychnos spinosa Lam., Garcinia livingstonei T.Anderson, Englerophytum magalismontanum (Sond.) T.D.Penn, Sclerocarya birrea (A.Rich) Hochst., Dovyalis caffra (Hook.f. \&
\end{abstract}

N. N. Nkosi - T. H. C. Mostert · N. R. Ntuli ( ()

Department of Botany, Faculty of Science and

Agriculture, University of Zululand, KwaDlangezwa,

Richards Bay 3886, South Africa

e-mail: NtuliR@unizulu.ac.za

\section{S. Dzikiti}

Council for Scientific and Industrial Research, Natural Resource and Environment, 11 Jan Cilliers Street,

Stellenbosch 7599, South Africa
Harv) Hook.f., Vangueria infaustia Burch. and Berchemia zeyheri (Sond.) Grubov. Strychnos spinosa was ranked as the first most important IFTs with a final score of 151, whereas Berchemia zeyheri was ranked the least with the final score of 146.1. However, the final scores of all most preferred species were relatively similar to one another. The top seven species identified in this study should be considered as a baseline for future IFTs development programmes such as domestication, whereby these species are introduced to small-holder farmers and food processing industries.

Keywords Indigenous fruit tree species . Domestication - Commercialization - Scorecard . Ranking system

\section{Introduction}

Indigenous fruit tree species (IFTs) are trees with edible fruits, which naturally grow within a specific geographic location and are often characterized by limited development relative to their potential (Mabhaudhi et al. 2017). South Africa has rich plant species diversity with numerous hotspots such as Maputaland and Pondoland Albany (Boon 2010). Some of these centers of plant endemism have a rich diversity of IFTs with economic potential as food crops. The exploitation of these species as a food source in certain rural 
areas of South Africa such as in Mpumalanga is well documented (Mashile et al. 2019). However, these species are still harvested from the wild despite their food security potential (Muok 2019). Therefore, there is a need to prioritize and introduce them as resources for small-scale farmers to ensure their continued contribution to food and income security (Jusu and Cuni-Sanchez 2017).

The domestication of IFTs starts by identifying priority species that have economic potential (Nieminen et al. 2017). The selection criteria for IFTs cultivation used by local farmers in Uganda is primarily based on cash value, food provision and to a lesser extent on medicinal value, length of the fruiting period, ease of propagation and drought resistance (Agea et al. 2007). Adansonia digitata L., Parinari curatellifolia Planch. Ex Benth., Sclerocarya birrea, Strychnos coculoides DC ex. Perleb and Uapaca kirkiana Muell. Arg. are perceived as the most important species for domestication in Malawi, Tanzania and Zimbabwe based on ethnobotanical surveys (Bvenura and Sivakumar 2017). However, the prioritization of IFTs differs based on the geographic location (Jusu and Cuni-Sanchez 2017).

Ethnobotanical studies and scorecard assessment methods are widely used for prioritizing IFTs with domestication and commercialization potential at a local level (Franzel et al. 2007; Jusu and Cuni-Sanchez 2017; Nieminen et al. 2017). However, such studies are few in South Africa. Therefore, the objective of this study was to prioritize IFTs with this potential in northern KwaZulu-Natal, South Africa, using focus group discussions, scorecard assessment and ranking system methods. One research question was addressed to plant experts: what should be the most preferred or prioritized IFTs in northern KwaZulu-Natal?

\section{Materials and methods}

Focus groups and ranking system

A list was compiled from the literature based on tree species that produce edible fruits, which are of African origin and are commonly found in South Africa including KwaZulu-Natal province (Table 1). Discussions with focus groups were held with representatives from organizations including the Council for Scientific and Industrial Research (CSIR), University of
Zululand, the Agricultural Research Council (ARC), iSimangaliso Nature Reserve, Ezemvelo KwaZuluNatal Wildlife, Siyazisiza Trust, Owen Sithole College of Agriculture, Transnet as well as independent consultants. The choice of representatives from these organizations was based primarily on people working predominantly with edible plants regarding their natural resources, propagation measures, and development of products from these plants. Therefore, these groups included agronomists, botanists, ecologists, hydro-scientists, food scientists and plant physiologists. Participants in four groups of six people each were informed that the purpose of the study was to prioritize species with domestication and commercialization potential. They were also invited to add other species through local taxonomy (naming of plants using isiZulu vernacular and/or English common names) if they were not included in the species list provided (Table 1). Scientific taxonomy through the recording of family, species and other common names; geographic distribution as well as uses of the added species were conducted using the literature.

Each group identified, with reasons for selection, a maximum of ten presumed most important species, either from the species list provided or from their own experience. The ten selected species were then ranked $1-10$ by each group corresponding to weights of $100-10 \%$ such that 1 was the highest rank given the weight of $100 \%$ and 10 was the lowest rank given the weight of $10 \%$. The results from all groups were then tallied and the number of times a species was given a particular rank was noted. An overall score was calculated as the sum of the products of the rank (\%) and the number of citations of a given species with that rank.

Scorecard assessment

A scorecard assessment, with individual species assigned eight different attributes, modified from Brehm et al. (2010) and Nieminen et al. (2017), was used to further trim the top ten species to seven, to score them based on the objective of this study (Table 2). Each attribute was given a pre-determined weight value from 2 to 5 , where 2 was the lowest value, indicating least desired attribute, and 5 the highest value indicating the most desired attribute for this study. A score out of eight for each attribute was assigned to each species, with the highest number 


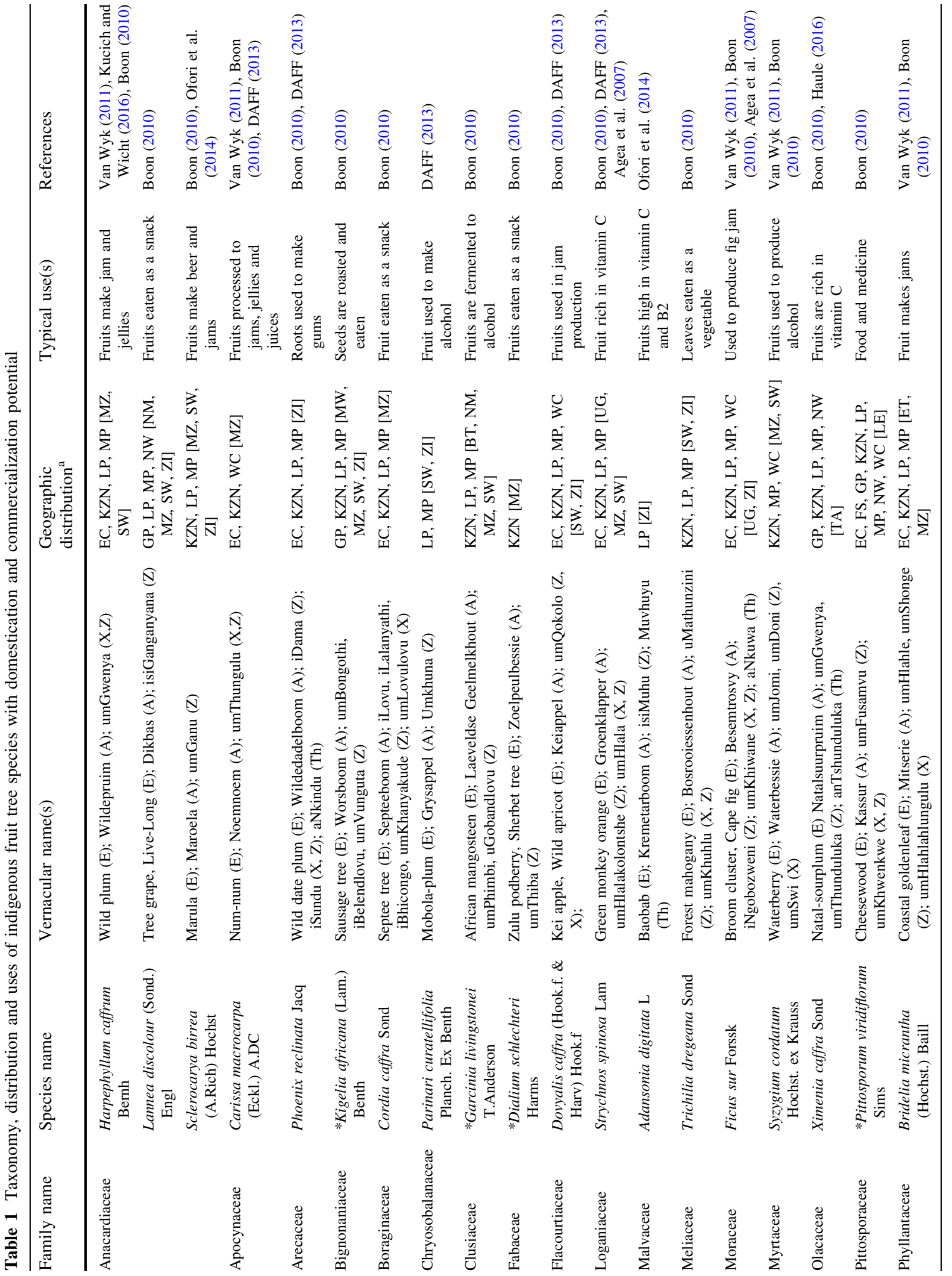




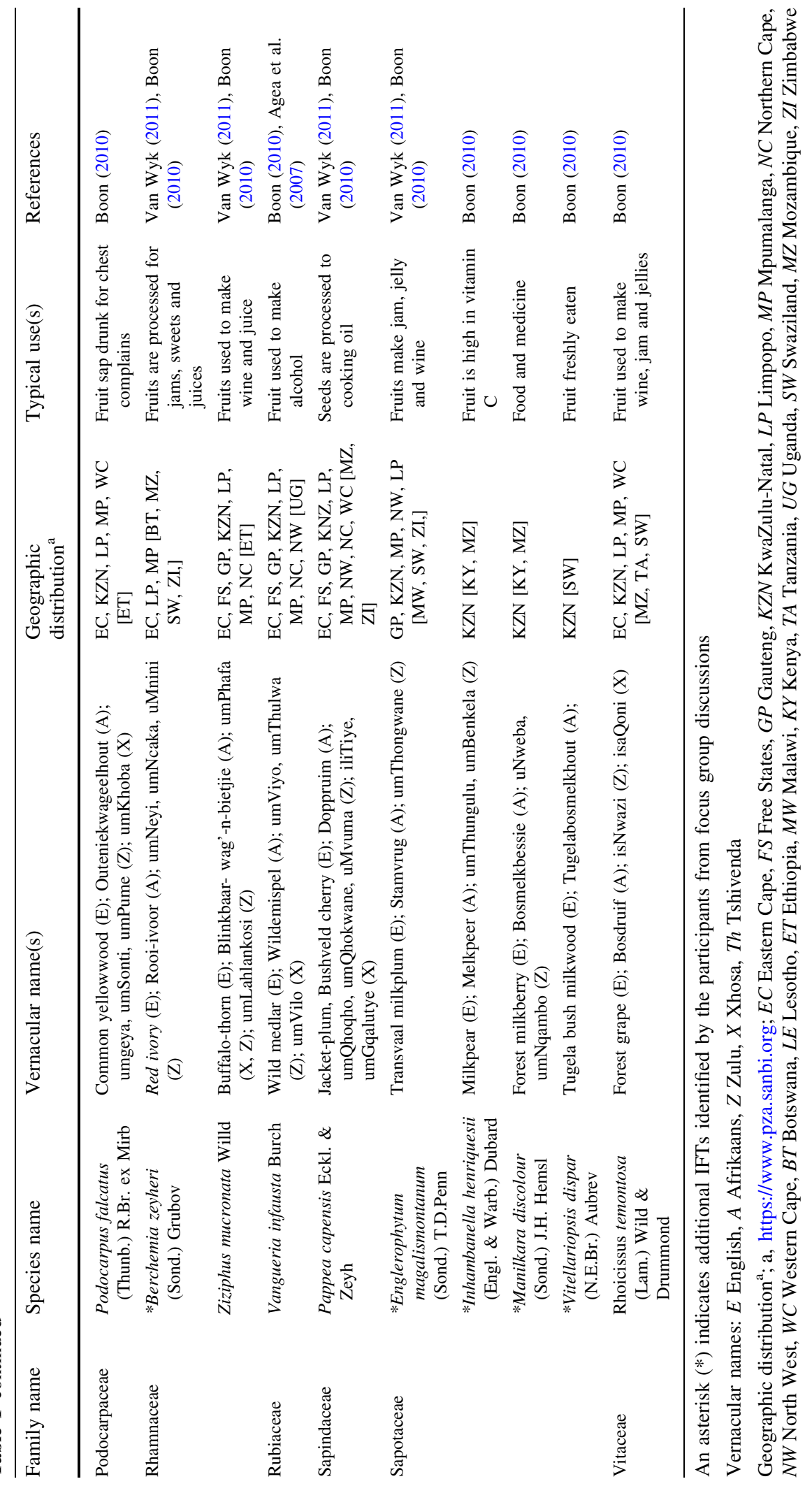


Table 2 The attributes and pre-determined weight values used in the scorecard assessment

\begin{tabular}{lll}
\hline Attributes & Category & $\begin{array}{l}\text { Weight } \\
\text { value (15) }\end{array}$ \\
\hline Value added products & A & 5 \\
Market demand for the products & B & 5 \\
Yield quality and quantity & C & 4 \\
Ability to locate study species/sites & D & 4 \\
Ease of propagation and regeneration & E & 4 \\
Ecological benefits & F & 3 \\
Disease and drought resistance & G & 3 \\
Other uses & H & 2
\end{tabular}

always indicating the highest priority. The overall score for each species was calculated as the sum of the product of the weight and assigned score (out of 8) for each attribute. A further reference group meeting was held with experts in horticulture, ecology, hydrosciences and plant genetics to discuss the feasibility of domesticating the seven prioritized species.

Data analysis

Data from literature search and participants were classified into different categories (Tables). Data from focus group discussions and ranking system were analysed descriptively using frequency citation and rank order priority percentages, where frequency citation was the number of groups which selected and ranked the same species. Scorecard data were analysed using Microsoft Excel and simple descriptive statistics.

\section{Results and discussion}

Indigenous fruit trees with domestication and commercialization potential

A total of 29 IFTs with domestication and commercialization potential were recorded, of which 20 were sourced from the literature and nine (represented by asterisks) were identified by participants in focus and reference groups (Table 1). A comparable study carried out in 15 villages of Limpopo listed 52 utilized fruit tree species, where only 33 were indigenous while 19 were exotic (Mashile et al. 2019). As the participants were given a species list to help with group discussions and invited to add any species not included, they probably concluded that species they initially found on the list were enough and added fewer species. Free-listing of species in the current study area could probably have yielded more species as in Rasethe et al. (2013).

The species recorded in the current study belonged to 29 genera and 23 families. Sapotaceae was the most dominant family, represented by four species, followed by Anacardiaceae ( 3 species) and Rhamnaceae (2 species), whereas the remaining families were represented by only one species each. All four species within the dominant Sapotaceae family (Englerophytum magalismontanum, Inhambanella henriquesii (Engl. \& Warb.) Dubard, Manilkara discolour (Sond.) J.H. Hemsl. and Vitellariopsis dispar) (N.E.Br.) Aubrev. were contributed to the list through focus group discussions than literature (Table 1), which is a benefit to numerous species documentation through the free-species listing (Rasethe et al. 2013). The dominance of species belonging to the Sapotaceae, Anacardiaceae and Rhamnaceae families was also recorded in the selection of preferred IFTs by rural communities in Mpumalanga (Mashile et al. 2019). These families, which mostly consist of trees, have a high economic value and are much preferred for their use as a source of fruits, firewood, medicine, timber and crafting (Rasethe et al. 2013). On the other hand, in Uganda, Arecaceae was the most dominant family represented by three species in which Phoenix reclinata Jacq. was within these species (Nieminen et al. 2017). Species endemism might have contributed to the other two species (Borassus aethiopium Mart. and Pseudospondias microcarpa Engl.) to be recorded only in Uganda.

Recorded species are known by different vernacular names across five ethnic groups namely, Afrikaans, English, Zulu, Xhosa and Tshivenda. Among these, a quarter of the species are known by the same vernacular name by at least two ethnic groups. Similar findings were recorded in Tanzania, where people use vernacular names in their languages for the indigenous species they use (Otieno et al. 2015). Rich vernacular diversity due to the broad ethnic spread of users' help to safeguard indigenous knowledge (Otieno et al. 2015). 
Recorded species are distributed throughout the provinces of South Africa with KwaZulu-Natal being the most represented location with the frequency index of $86 \%$ followed by Limpopo (76\%) and least represented in Northern Cape (10\%). Most of these species thrive in warm and dry climatic conditions which are more experienced in KwaZulu-Natal and Limpopo provinces (DAFF 2013). All species also occur in at least one African country in addition to South Africa. This suggests that Africa has a rich diversity of IFTs with domestication and commercialization potential. Fifty-five percent of listed species are processed into various products such as culinary oils, beverages, jams, jellies and sweets. A comparable study reported that most IFTs have the potential to produce new food products for local and international markets (Van Wyk 2011).

Focus groups and ranking system

The participants identified; with their reasons, Strychnos spinosa, Syzygium cordatum Hochst. ex Krauss, Sclerocarya birrea, Dovyalis caffra, Ximenia caffra Sond., Vangueria infausta, Harpephyllum caffrum Bernh., Englerophytum magalismontanum, Garcinia livingstonei and Berchemia zeyheri as ten priority species that belong to nine families (Table 3). Comparable studies from Limpopo (Rasethe et al. 2013) and Mpumalanga (Mashile et al. 2019) recorded; among others, H. caffrum, S. birrea, S. spinosa and $V$. infausta as the most utilized or preferred IFTs. These similarities in local preferences may be linked to the abundance and usefulness of these species in different areas (Jusu and Cuni-Sanchez 2017).

The Anacardiaceae was the most represented family with two species, namely, $H$. caffrum and $S$. birrea whereas the remaining families were presented by one species each. Similar findings on the utilization of plant resources were noted where the Anacardiaceae was represented by the most species (Rasethe et al. 2013). Two groups ranked $S$. birrea as the first most important species whereas two groups ranked $S$. spinosa as the second-most important species. However, S. spinosa had the highest score (320) compared to $S$. birrea (260); B. zeyheri had the lowest score (80).

The reasons for selection included species abundance, drought resistance, high commercial value and food value. Forty percent of the prioritized species were chosen because they have multiple-uses. This finding is in agreement with studies in Limpopo (Rasethe et al. 2013). Provided that most of these species are still harvested from the wild, multiutilization can lead to overharvesting and extinction (Fukushima et al. 2010). Ethnobotanical studies, through focus group discussions alone, are not able to identify indigenous fruit tree species with commercialization potential as participants list species based on only personal preferences such as taste. In a study carried out in Bushbuckridge, Mpumalanga, 55\% of participants preferred certain indigenous fruits based on taste whereas only $3 \%$ accounted for economic value as a reason for preference (Shackleton et al. 2002). Focus group discussions should be accompanied by preference rankings taking into account the objectives of the study other than only personal preferences (Nieminen et al. 2017).

Scorecard assessment

The top seven IFTs identified in order of the most to the least preferred species were $S$. spinosa, $G$. livingstonei, E. magalismontanum, S. birrea, D. caffra, $V$. infausta and B. zeyheri (Table 4). Similarly, in Malawi, Tanzania and Zimbabwe, S. birrea was one of the five most prioritized species (Bvenura and Sivakumar 2017). Preference of this species at a countrywide level is probably due to value-added opportunities that have been explored in numerous industries including, beverages and cosmetics (Akinnifesi et al. 2006). In contrast, A. digitata and $P$. curatellifolia that were among the five prioritized species in Southern Africa (Bvenura and Sivakumar 2017), and were on the main list of plants in the current study, were not prioritized. These species might not be abundant in KwaZuluNatal, and thus participants probably opted for species widely distributed in the area of interest. Species that are more abundant are more likely to be prioritized (Nieminen et al. 2017).

Seventy percent of the prioritized species in the current study are from the species list generated from literature whereas, 30\% came from the participants added species. Participants tend to probe for species on the provided list (Nieminen et al. 2017). Strychnos spinosa was ranked as the first most preferred indigenous fruit tree species with a final score of 151 whereas $B$. zeyheri was ranked least with a final score of 146.1. Although these species are ranked in descending order, they are all equally preferred 


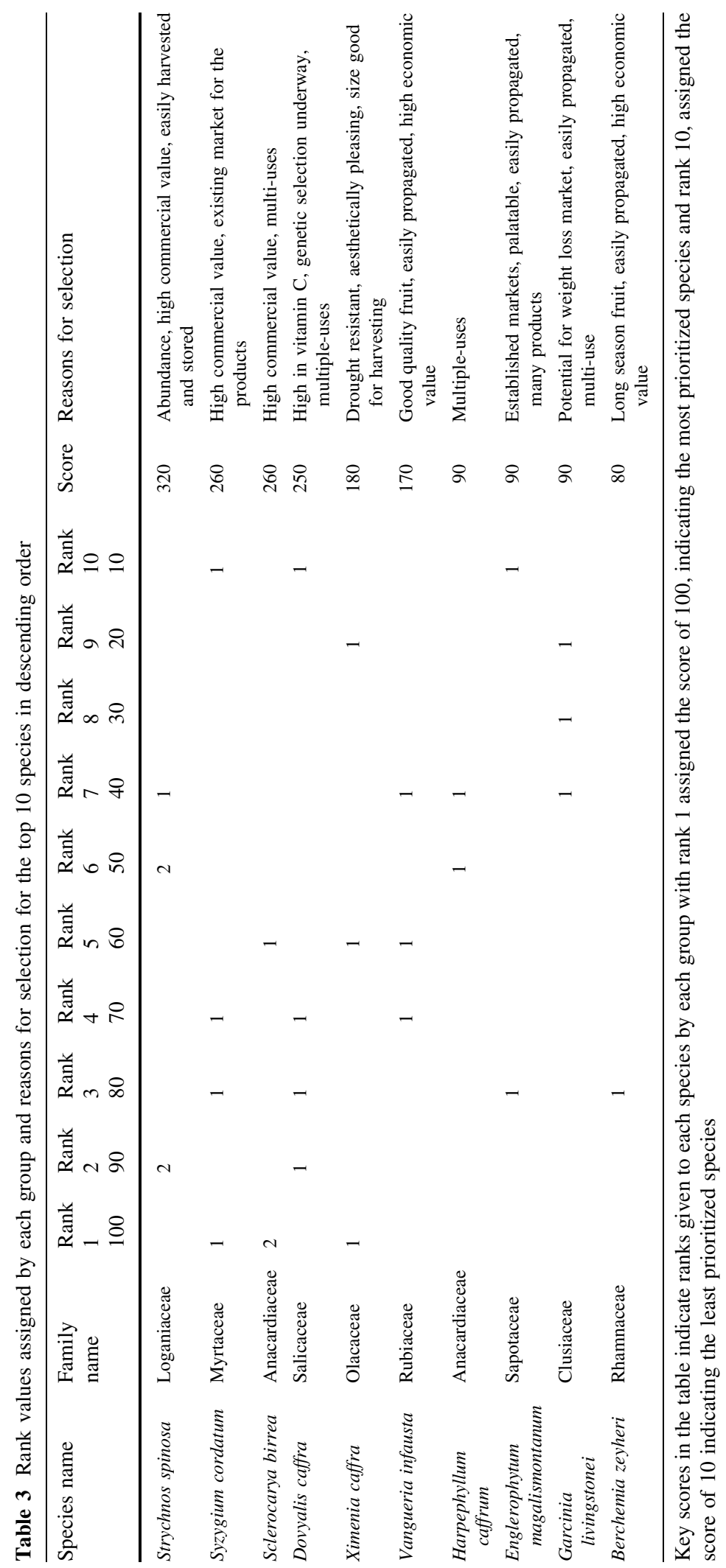


Table 4 The top 7 species in descending order

\begin{tabular}{|c|c|c|c|c|c|c|c|c|c|c|}
\hline \multirow[t]{2}{*}{ Scientific species names } & \multicolumn{8}{|c|}{ Weighted attributes (/5) } & \multirow[t]{2}{*}{ Final score } & \multirow[t]{2}{*}{ Final rank } \\
\hline & $\begin{array}{l}5 \\
\text { Ct. A }\end{array}$ & $\begin{array}{l}5 \\
\text { Ct. B }\end{array}$ & $\begin{array}{l}4 \\
\text { Ct. C }\end{array}$ & $\begin{array}{l}4 \\
\text { Ct. D }\end{array}$ & $\begin{array}{l}4 \\
\text { Ct. E }\end{array}$ & $\begin{array}{l}3 \\
\text { Ct. F }\end{array}$ & $\begin{array}{l}3 \\
\text { Ct. G }\end{array}$ & $\begin{array}{l}2 \\
\text { Ct. H }\end{array}$ & & \\
\hline Strychnos spinosa & 8 & 6 & 7 & 4 & 5 & 1 & 3 & 2 & 151 & $1 \mathrm{st}$ \\
\hline Garcinia livingstonei & 7 & 8 & 6 & 5 & 4 & 1 & 2 & 3 & 150.2 & 2nd \\
\hline Englerophytum magalismontanum & 6 & 8 & 7 & 5 & 4 & 1 & 2 & 3 & 149.3 & $3 r d$ \\
\hline Sclerocarya birrea & 7 & 8 & 6 & 5 & 3 & 2 & 1 & 4 & 148.8 & 4 th \\
\hline Dovyalis caffra & 8 & 5 & 7 & 4 & 6 & 1 & 2 & 3 & 148.7 & 5 th \\
\hline Vangueria infausta & 7 & 6 & 8 & 5 & 4 & 1 & 2 & 3 & 148.5 & 6 th \\
\hline Berchemia zeyheri & 7 & 8 & 6 & 4 & 3 & 2 & 1 & 5 & 146.1 & 7 th \\
\hline
\end{tabular}

Key scores in the table indicate assigned scores out of 8 for each attribute, giving the final rank of each species in the descending order

Ct. categories that are explained in Table 2

because their final scores are relatively similar. In a scorecard assessment species may have identical scores for entirely different reasons (Brehm et al. 2010). Although $S$. spinosa was ranked as the first most preferred species, it scored the lowest in the species abundance attribute (4/8). Similarly, this species was ranked number 12 in the top 15 species prioritized for on-farm cultivation by Uganda farmers based on taste and its scarcity on farms might have led to such a ranking (Agea et al. 2007).

Vangueria infausta scored 8 in the yield quality and quantity attribute. A comparable study recorded that the fruit yield of $V$. infausta is prolific and superior to some equally important IFTs (Mng'omba et al. 2011). G. livingstonei, E. magalismontanum, S. birrea and B. zeyheri were scored as the most priority species with market demand for the products. This attribute suggests that it is easier to sell the products of these species (Nieminen et al. 2017). D. caffra followed by $S$. spinosa are easier to propagate and regenerate. Consequently, less labour is required when domesticating such species, thus more likely to be prioritized for cultivation (Mashela and Mollel 2001). Species were scored from 1-3 in the pests, diseases and drought resistance attribute in which $S$. spinosa was the most prioritized species in this attribute. Frequent irrigation is expensive, thus prioritization of droughttolerant species is often favoured (Ngemakwe et al. 2017). B. zeyheri has numerous uses and scored 5 whereas $S$. spinosa scored least in this attribute. However, if a species has other uses in addition to food use, it is likely to be prioritized but can be prone to numerous factors such as overharvesting (Nieminen et al. 2017).

\section{Conclusion and recommendations}

According to scorecard assessment, all the IFTs assigned priority status, namely; Strychnos spinosa, Garcinia livingstonei, Englerophytum magalismontanum, Sclerocarya birrea, Dovyalis caffra, Vangueria infausta and Berchemia zeyheri, qualify for domestication programmes in northern KwaZuluNatal. The next step is to find sites which harbour these species in that part of the province and study their phenology, yield and water use requirements prior to domestication initiatives.

Acknowledgements We thank the Council for Scientific and Industrial Research and the Water Research Commission (Project WRC K5/2720/4) for financial support. We further extend our gratitude to the focus group and reference group participants for their invaluable inputs in this study.

\section{Compliance with ethical standards}

Conflict of interest There are no conflicts of interest.

Open Access This article is licensed under a Creative Commons Attribution 4.0 International License, which permits use, sharing, adaptation, distribution and reproduction in any medium or format, as long as you give appropriate credit to the original author(s) and the source, provide a link to the Creative Commons licence, and indicate if changes were made. The images or other third party material in this article are included in the article's Creative Commons licence, unless indicated otherwise in a credit line to the material. If material is not 
included in the article's Creative Commons licence and your intended use is not permitted by statutory regulation or exceeds the permitted use, you will need to obtain permission directly from the copyright holder. To view a copy of this licence, visit http://creativecommons.org/licenses/by/4.0/.

\section{References}

Agea JG, Obua J, Kaboggoza JRS, Waiswa D (2007) Diversity of indigenous fruit trees in the traditional cotton-millet farming system: the case of Adwari subcountry, Lira District. Uganda Afr J Ecol 45(3):39-43

Akinnifesi FK, Kwesiga F, Mhango J, Chilanga T, Mkonda A, Kadu CAC, Kadzere I, Mithofer D (2006) Towards the development of Miombo fruit trees as commercial tree crops in Southern Africa. Forests Trees Livelihoods 16(1):103-121

Boon R (2010) Pooley's trees of Eastern South Africa, a complete guide. Flora \& Fauna Publications Trust, Totnes

Brehm JM, Maxted N, Martins-LoucaoFord-Lloyd MABV (2010) New approaches for establishing conservation priority for socio-economically important plant species. Biodivers Conserv 19:2715-2740

Bvenura C, Sivakumar D (2017) The role of wild fruits and vegetables in delivering a balanced and healthy diet. Food Res Int 99:15-30

DAFF (2013) Department of Agriculture, Forestry and Fisheries. Most common indigenous food crops of South Africa. pp 1-28

Fukushima T, Morimoto Y, Maundu P, Kahindi B, Fondo J (2010) Local preference of indigenous fruit trees in Coast Province, Kenya. Afr J Environ Sci Technol 4(12):872-885

Franzel S, Akinnifesi FK, Ham C (2007) Setting priorities among indigenous fruit tree species in Africa: Examples from southern, eastern and western regions. CAB International, Wallingford

Haule MJ (2016) Indigenous fruits business and conservation of edible indigenous fruit trees in Songea District, Tanzania. Int J Dev Res 6(8):8978-8984

Jusu A, Cuni-Sanchez A (2017) Priority indigenous fruit trees in the African rainforest zone: insights from Sierra Leone. Genet Resour Crop Evol 64:745-760

Kucich DA, Wicht MM (2016) South African indigenous fruits - underutilized resource for boosting daily antioxidant intake among local indigent populations. S Afr J Clin Nutr 29(4):150-156
Mabhaudhi T, Chimonuo VGP, Modi AT (2017) Status of underutilised crops in South Africa: opportunities of developing reseach capacity. Sustainability 9:1-21

Mashela PW, Mollel N (2001) Farmer-identified indigenous fruit tree with suitable attributes for the semi-arid northern province of South Africa. S Afr J Agr 30:1-12

Mashile SP, Tshisikwawe MP, Masevhe NA (2019) Indigenous fruit plants of the Mapulana of Enhlanzeni district in Mpumalanga province, South Africa. S Afr J Bot 122:180-183

Mngomba SA, Akinnifesi FK, Sileshi G, Ajayi OC, Nyoka BI, Jamnadass R (2011) Water application rate and frequency affect seedling survival and growth of Vangueria infausta and Persea americana. Afr J Biotech 10(9):1593-1599

Muok BO (2019) Potential and utilization of indigenous truit trees for food and nutrition security in East Africa. Glob Adv J Agric Sci 8(2):40-49

Nieminen R, Sørensen M, Theilade I (2017) Identification of indigenous fruits with export potential from Mukono district, Uganda: an assessment of two methods. Agrofor Syst 91:967-979

Ngemakwe NPH, Remize F, Thaoge ML, Sivakumar D (2017) Phytochemical and nutritional properties of underutilised fruits in the southern African region. S Afr J Bot 113:137-149

Ofori DA, Gyau A, Dawson IK, Asaah E, Tchoundjeu Z, Jamnadass R (2014) Developng more productive African agroforestry systems and improving food and nutritional security through tree domestication. Curr Opin Environ Sustain 6:123-127

Otieno J, Abihudi S, Veldman S, Nahashon M, Van Andel T, De Boer HJ (2015) Vernacular dominamnce in folk taxonomy: a case study of ethnospecies in medicinal plant trade in Tanzania. J Ethnobiol Ethnomed 11(10):1-7

Rasethe MT, Semenya SS, Potgieter MJ, Maroyi A (2013) The utilization and management of plant resources in rural areas of the Limpopo Province, South Africa. J Ethnobiol Ethnomed 9(27):1-8

Shackleton CM, Dzerofos CM, Shackleton SE, Mathabela FR (2002) The use and trade in indigenous edible fruits in the Bushbuckridge savanna region, South Africa. Ecol Food Nutr 39:225-245

Van Wyk BE (2011) The potential of South African plants in the development of new food and beverage products. S Afr J Bot 77:857-868

Publisher's Note Springer Nature remains neutral with regard to jurisdictional claims in published maps and institutional affiliations. 